\title{
Semantic satiation affects category membership decision time but not lexical priming
}

\author{
LEE C. SMITH \\ Dalhousie University, Halifax, Nova Scotia, Canada
}

\begin{abstract}
Experiments 1 and 2 examined the effects of semantic satiation on category membership decision latency. Subjects overtly repeated the name of a category either 3 or 30 times, and then decided whether or not a target exemplar was a member of the repeated category. Experiment 1 obtained some evidence that member decisions are slower and nonmember decisions are faster following 30 repetitions, but only the interaction was reliable. Experiment 2 confirmed only that member decisions are slower following satiation of the category name. The results support the hypothesis that prolonged repetition of a word reduces the availability of semantic information related to that word. Experiment 3 showed that the magnitude of priming in the lexical decision task is unaffected by satiation of the prime. Several general approaches to understanding semantic satiation are discussed. The most parsimonious account assumes that satiation affects the links or pathways connecting concepts in the satiated category. The net effect is to decrease the rate of search and associative spread of activation in conceptual structures.
\end{abstract}

Semantic satiation refers to the apparent loss or attenuation of the meaning of a word as a result of massed overt repetition. The reader may quickly experience this phenomenon by repeating (probably) any word for about 20-30 sec. After the first paper on semantic satiation appeared (Severance \& Washburn, 1907), a substantial literature developed in the effort to demonstrate the semantic character of the effect of satiation. At the time of Esposito and Pelton's (1971) comprehensive review of the semantic satiation literature, the measurement of the effect of satiation included subjective report, the commonality and number of associates generated to the satiated word, and synonym judgment and associate retrieval time. According to Esposito and Pelton, this literature provides inconsistent support for the semantic satiation hypothesis and results that are open to alternative explanation.

More recently, Neely (1977a) reported an experiment that applied the semantic priming paradigm to the semantic satiation phenomenon. The finding that lexical (wordnonword) decisions are faster when a target word is preceded by a semantically related prime word than when it is preceded by a neutral or semantically unrelated prime (Antos, 1979; Neely, 1977b) suggests that this task may provide a good demonstration of semantic satiation. Specifically, Neely argued that the semantic satiation hypoth-

This research was supported by a NSERC Canada grant held by Raymond Klein. Thanks are extended to Raymond Klein for support and extensive comments on earlier versions of this paper. Thanks are also extended to James Neely and David Balota for their valuable comments, and to Lynnette Koshman, David Pilon, and John Logan for their assistance in data collection. Requests for reprints should be sent to Lee C. Smith, Department of Psychology, Erindale College, University of Toronto, Mississauga, Ontario, Canada L5L 1C6. esis predicts that the priming effect observed with related primes will be diminished if the prime word is repeated and hence is semantically satiated: Satiation would reduce or eliminate activation of the prime, and accordingly reduce or eliminate spreading activation (Collins \& Loftus, 1975) to semantically associated structures. This would be seen as a reduction in the magnitude of the priming effect following satiation.

Neely's (1977a) experiment found no evidence to support this prediction. However, Neely used an 11-sec repetition period, which may be too short for sufficient satiation to develop. Cohene, Smith, and Klein (1978) tested the semantic satiation hypothesis by having subjects first pronounce a prime word either once or repeatedly for $30 \mathrm{sec}$ and then make a lexical decision about a target item. In their Experiments 1 and 3, the target words were either associatively related or unrelated to the prime word, and in their Experiment 2, the target words were either identical to or unassociated with the prime word. These experiments also obtained no evidence of an effect of satiation on the magnitude of semantic priming, although the response time (RT) was faster to related (or identical) targets than to unrelated targets, which would be expected with their priming procedure. Cohene et al. concluded that semantic satiation is "not truly related to the loss of meaning of a word" (p. 139; and see Esposito \& Pelton, 1971, p. 344, for a similar conclusion).

An alternative position is that priming with the lexical decision task is not sensitive to semantic satiation. First, a lexical decision involves deciding whether or not a target item has a corresponding entry in the subjective lexicon (Miller, 1978), which may not require retrieval of 
any semantic information about the target (cf. Balota \& Chumbley, 1984). Second, the possibility that lexical priming is mediated by mechanisms or structures that are different from those that are affected by the satiation treatment cannot be ruled out on the basis of existing data. This suggests that a clearer test of semantic satiation requires a task that entails a decision that depends on information about both the satiated word and the target.

\section{EXPERIMENT 1}

The following experiment required subjects to pronounce the name of a category (e.g., FRUIT) either 3 or 30 times, and then to decide whether or not a target word (e.g., APPLE, ROBIN) was an instance of the repeated category. A category membership decision requires the retrieval of some of the semantic properties of both the category name and target word. If the satiation phenomenon does reflect a reduction in the availability of semantic information related to the satiated word, then responses to member targets should be slower following 30 repetitions than following 3 repetitions.

\section{Method}

Subjects. Eight female and eight male introductory psychology students participated in the experiment for course credit. All subjects were native English speakers.

Stimuli and Apparatus. The priming words were 40 category names, and the targets were 1 exemplar from each of the 40 categories. Two lists of 40 category-exemplar pairs were constructed (these are listed in the Appendix). Each list contained 20 exemplars paired with their derivative category names (member condition) and 20 paired with other category names (nonmember condition). A target served as a member in one list and as a nonmember in the other list. A similar list of 16 new word-pairs was used for practice.

The stimuli were shown on a Tektronix 604 cathode-ray tube controlled by a PDP-11/03 computer. The words were plotted in capital letters, and subtended, on average, about $.68^{\circ} \times 1.06^{\circ}$ of visual angle at the viewing distance of about $29 \mathrm{~cm}$. The subjects signaled their responses with one of two response switches mounted in Plexiglas and resting on the table. An intercom allowed the experimenter to monitor the subjects' repetitions in an adjoining room.

Procedure. The subjects were tested individually in a single session lasting about $35 \mathrm{~min}$. Each subject completed 16 practice and 40 experimental trials. Each subject was tested with only one of the two experimental lists. The experimental series comprised 10 trials in each of the four conditions derived from the combination of type of relation (member, nonmember) with number of repetitions $(3,30)$. The assignment of items to conditions was counterbalanced across subjects. The order of trials was randomized for each subject.

A trial began with the appearance of a fixation point in the center of the screen. One second later, a category name appeared in two locations, about $1^{\circ}$ above and below the fixation point. The category name was displayed either 3 or 30 times for $500 \mathrm{msec}$, with a 200 -msec interval between exposures. The subjects were instructed to pronounce the category name clearly and to begin articulation of the word coincidentally with its appearance on the screen. The subjects were told that the experimenter would be monitoring their repetitions via the intercom.

After the final repetition, the fixation point was brightened for $1 \mathrm{sec}$ to serve as a warning signal. The target word was then written on the screen, centered at the fixation point, until the subjects responded. The subjects received no feedback. The intertrial interval was $5 \mathrm{sec}$. Half of the subjects signaled "member" with the left index finger and "nonmember" with the right index finger, and the other half had the reverse mapping.

\section{Results}

The median RTs for the correct category membership decisions and the percent error data for the experimental trials were subjected to separate two-way analyses of variance including the factors type of decision and number of repetitions.

The mean median RTs and percent errors are shown in Figure 1a. The member decisions were $110 \mathrm{msec}$ faster than the nonmember decisions $[F(1,15)=44.16$, $\mathrm{p}<.05]$. There was no reliable difference between decision times as a function of the number of repetitions $[\mathrm{F}(1,15)<.2]$. The significant interaction of decision type with number of repetitions $[F(1,15)=6.04$, $\mathrm{p}<.05$ ] suggests that member decisions were slower following 30 repetitions and nonmember decisions were faster following 30 repetitions. Two-tailed t tests showed that neither of these differences was reliable $[t(15)=1.57$, $p>.05$, for the member condition; $t(15)=1.79$, p $>.05$, for the nonmember condition]. A similar analysis of variance of the percent error data showed no main effect of type of decision $[F(1,15)=2.01]$. The interaction of type of decision and number of repetitions did not approach significance $[F(1,15)=1.77]$.

\section{Discussion}

The results of Experiment 1 are consistent with the idea that satiation of semantic information about a category occurs following repeated pronunciation of the category name. The observation that the subjects were slower to correctly decide that an exemplar was a member of the primed category following 30 repetitions is predicted by the semantic satiation hypothesis. Unexpectedly, the subjects' responses were faster following 30 repetitions when the subjects were correctly deciding that a target was not a member of the category. These trends account for the obtained interaction of decision type with number of repe-

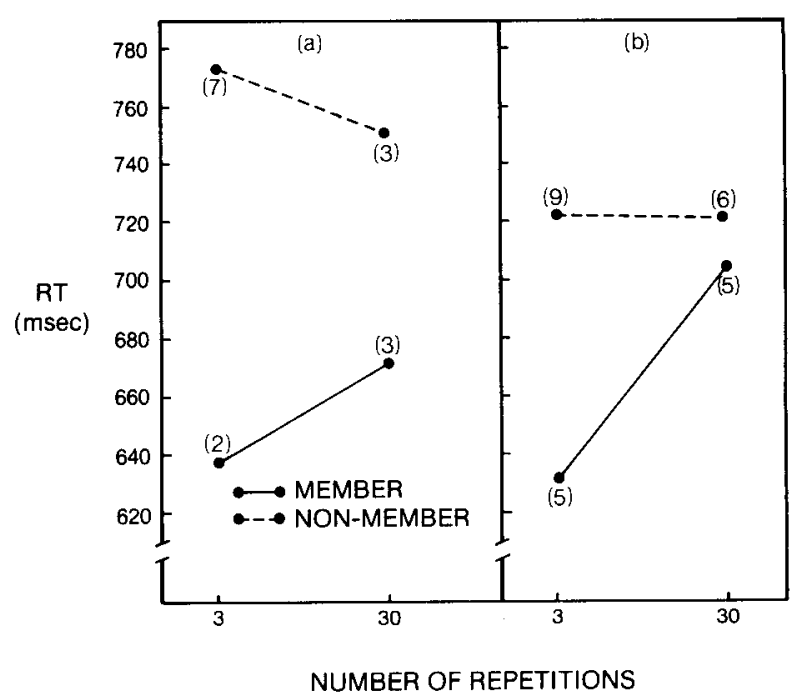

Figure 1. Mean median RT as a function of number of repetitions and type of decision. Panel a: Experiment 1. Panel b: Experiment 2. 
titions. However, neither of these isolated effects was shown to be reliable. Therefore, since no decisive statement regarding the semantic satiation hypothesis can be extracted from these data, the category membership experiment was repeated with twice the number of subjects in an attempt to unequivocally confirm or refute the impressions derived from Experiment 1. In the replication, subjects were given RT feedback following each of their responses to encourage faster responding and to thereby shift their performance away from the asymptote on the speed-accuracy tradeoff function (see Pachella, 1974). Also, the category name was presented in only one location on the screen. It was felt that neither of these changes would influence the phenomenon of interest.

\section{EXPERIMENT 2}

\section{Method}

Subjects. Thirty-two paid subjects were recruited from the Dalhousie University subject pool. Half of the subjects were male, and half were female. All subjects were native English speakers, and none had participated in Experiment 1.

Procedure. All aspects of the experiment were identical to those of Experiment 1, with the exceptions that the subjects received RT feedback following each trial and that the category name was presented only above the fixation point (as opposed to above and below fixation).

\section{Results}

Figure $1 \mathrm{~b}$ shows the mean median RTs and mean percent errors. Member decisions were $53 \mathrm{msec}$ faster than nonmember decisions $[F(1,31)=6.71, p<.05]$. For member decisions, the subjects were reliably slower following 30 than following 3 repetitions [ $\mathrm{t}(31)=2.55, \mathrm{p}<.05]$. There was no effect of repetition for nonmember decisions $[\mathrm{t}(31)=.54]$. Similar tests on the percent errors showed that there was no effect of number of repetitions for either the member $[t(31)=0.0]$ or nonmember $[t(31)$ $=1.27$ ] conditions.

Although the trend for accuracy to improve for nonmember decisions with 30 repetitions was not statistically reliable, it might be suggested that the RT data are potentially open to a response-bias interpretation: The subjects are slower to make member decisions following 30 repetitions because they developed a bias to respond nonmember. In its purest form, the response-bias account requires a reciprocal relation between speed and accuracy. However, examination of Figure $1 \mathrm{~b}$ shows no change in accuracy for member decisions and no decrease in RT for the nonmember condition. The pattern of RT and accuracy in Experiment 2 is not in complete agreement with the response-bias account. Also, when we examined the data from only those subjects (N=6) showing an increase in errors in the nonmember condition between 3 and 30 repetitions (the opposite of the response-bias prediction), RT increased by $117 \mathrm{msec}$ with number of repetitions in the member condition. For subjects with fewer errors in the 30- relative to the 3-repetition nonmember condition $(\mathrm{N}=10)$, member RT increased by $65 \mathrm{msec}$, and for the subjects that showed no change in nonmember error rate $(\mathrm{N}=16)$, member RT increased by $60 \mathrm{msec}$ with repe- tition period. Thus, there is no evidence to support a response-bias interpretation of the RT data.

\section{Discussion}

The semantic satiation hypothesis maintains that activation of semantic information about a word is fatigued following extended repetition of the word. The substantial body of work reviewed in Esposito and Pelton (1971) deployed a range of tasks to test this hypothesis, but the findings were generally mixed or were difficult to interpret. Neely (1977a) tested the semantic satiation hypothesis with the semantic priming-lexical decision task and obtained disconfirming evidence. Cohene et al. (1978) had subjects repeat a prime word once or for $30 \mathrm{sec}$ and measured lexical decision latencies. No differential priming effect was obtained for associated and unassociated or identical and unassociated word targets as a function of repetition period.

Experiments 1 and 2 were based on the premise that the priming-lexical decision task may be insensitive to the effect of satiation, given the possibilities that the information that is satiated does not mediate priming and/or is not part of the basis of a lexical decision. To circumvent this criticism, we had subjects pronounce the name of a category either 3 or 30 times and then perform a speeded category membership decision with target words that were or were not exemplars of the repeated category. Experiment 1 obtained some evidence to indicate that member decisions (e.g., prime-WEAPON, target-GUN) were slower following 30 repetitions, a finding that is consistent with the semantic satiation hypothesis. Also, data from Experiment 1 suggested that nonmember decisions (e.g., WEAPON-JAZZ) were facilitated following 30 repetitions. The replication experiment confirmed only that member decisions are slower following the satiation treatment. No effect of repetition was obtained for nonmember decisions.

First of all, these results are clearly supportive of the general nature of the semantic satiation hypothesis. Second, the differential effect of satiation with the priminglexical decision (Cohene et al., 1978) and category membership tasks potentially bears interesting implications for semantic priming theory (Collins \& Loftus, 1975; Neely, 1977b). However, pertaining to the latter point, we note that it seems possible that procedural and/or stimulus material differences between the Cohene et al. and our Experiments 1 and 2 may account for the different effects of satiation noted. Since it is clearly necessary to unequivocally establish whether or not the apparent task difference in the effect of satiation is actual, we conducted the following experiment using the priming-lexical decision task and the same materials and procedure as in Experiments 1 and 2, insofar as the task change would allow.

\section{EXPERIMENT 3}

\section{Method}

Subjects. Sixteen male and 16 female introductory psychology students participated in the experiment for course credit. None had partic- 
Table 1

Mean Response Times (RTs) and Percent Errors (PEs) for Related and Unrelated Target Words and for Nonwords for the 3- and 30-Repetition Conditions, Experiment 3

\begin{tabular}{|c|c|c|c|c|c|c|}
\hline \multirow{2}{*}{$\begin{array}{l}\text { Number of } \\
\text { Repetitions }\end{array}$} & \multicolumn{2}{|c|}{ Related } & \multicolumn{2}{|c|}{ Unrelated } & \multicolumn{2}{|c|}{ Nonwords } \\
\hline & RT & PE & RT & $\mathrm{PE}$ & RT & PE \\
\hline 3 & 622 & 5.6 & 696 & 12.5 & 766 & 8.7 \\
\hline 30 & 627 & 7.5 & 693 & 15.0 & 779 & 7.2 \\
\hline
\end{tabular}

ipated in the previous experiments. All subjects were native English speakers.

Stimuli. The same materials were used as before. In addition, 40 pronounceable, orthographically legal nonwords were generated by changing a single letter in each of the 40 target words. Four stimulus lists of 40 pairs each were constructed such that each list contained 10 semantically related (formerly member) pairs, 10 semantically unrelated (formerly nonmember) pairs, and 20 category name-nonword pairs. Each category name appeared once in each list, and across lists was paired once with an exemplar, once with an unrelated word, and with 2 nonwords that were not derived from an exemplar of that category. A similar list of 16 new pairs was developed and used for practice.

Procedure. The experiment followed essentially the same procedure as that of Experiment 2. The subjects were instructed to make wordnonword decisions about the target item that followed the repetition period on each trial, and to emphasize both response speed and accuracy. The subjects also were told about the relations between the category names and target words. Following practice, a subject received the 40 experimental trials from one of the four lists. The experimental series comprised 5 trials in each of the four conditions derived from the combination of type of relation (related, unrelated) with number of repetitions of the category name $(3,30)$, and 10 nonword trials in each repetition condition. The assignment of items to conditions was counterbalanced across subjects. Half of the subjects signaled "word" with the left index finger and "nonword" with the right index finger, and the other half had the reverse mapping.

\section{Results}

The mean median RTs and percent errors are given in Table 1. The RT to related targets was $70 \mathrm{msec}$ faster than the RT to unrelated targets $[\mathrm{F}(1,31)=22.4, \mathrm{p}<.05]$, evidencing the typical priming effect. There was no difference in RT as a function of number of repetitions for either the related or the unrelated conditions (both $t$ values $<.39$ ), and no difference in the analyses of the percent errors (both $t$ values $<.83$ ). Similarly, the analyses of the nonword RTs and percent errors showed no reliable differences between repetition conditions [ $\mathrm{t}(31)$ $=1.03$ and .87 , respectively].

\section{GENERAL DISCUSSION}

The results of the present experiments have demonstrated that satiation of a category name (1) increases category membership decision time for exemplars, (2) does not affect category decision time for nonexemplars, and (3) does not influence priming with the lexical decision task (replicating the findings of Cohene et al., 1978; see also Neely, 1977a). The results are consistent with the idea that repeated pronunciation of a word affects the accessibility of semantic information related to that word.

Many general theoretical approaches to these data can be found in the burgeoning literature on inhibitory semantic priming effects. However, the evidence of inhibition from prior exposure to semantically related material is derived from a variety of methodologies, including episodic recognition (Neely, Schmidt, \& Roediger, 1983; Roediger \& Neely, 1982) and recall (Mueller \& Watkins, 1977), alphanumeric matching (Neill, 1979), target generation (Blaxton \& Neely, 1983; Brown, 1981), and category matching (under certain conditions; Rosch, 1975). A theoretical integration of that literature with the present data will not be attempted here. Instead, borrowing from some of that work, several general accounts of the present data will be outlined.

First, given that nonexemplars showed no effect of satiation in the category membership task, we might hypothesize that the effect of satiation may be limited to reducing the accessibility of (the meaning of) exemplars of the category. Subjects may covertly but actively retrieve many exemplars from the category in anticipation of an exemplar target (Blaxton \& Neely, 1983). To sustain retrieval of new candidate target exemplars during the extended, 30-repetition period, items that had been retrieved initially might need to be inhibited, effectively increasing RT for these latter items. A variant of this position is that prolonged retrieval of intracategory items may instill a global retrieval block of exemplars (see Blaxton \& Neely, 1983, Keele \& Neill, 1978, and Raaijmakers \& Shiffrin, 1981). Accounts of this type assume that the observed effect of satiation arises not from repetition and satiation of the category name per se, but from prolonged implicit recollection of exemplars. However, the informal reports by our subjects indicated that they were quite occupied by the rapid pronunciation task itself $f^{1}$ and that they did not claim to actively recall as many exemplars as possible. Nonetheless, these ideas remain plausible.

A parallel-access model, along the lines of Morton's $(1970,1979)$ logogen model, or that makes use of the resonance metaphor (e.g., Gordon, 1983; Ratcliff, 1978), provides a second accommodation for the category membership data. Upon presentation and pronunciation of a word, the logogen for that word and other logogens that are orthographically, phonemically, and semantically similar will be activated. Initially, this would generally facilitate retrieval of information in aroused logogens. However, if logogens can be fatigued by prolonged activation (e.g., Martindale, 1981, p. 199), as in the satiation treatment, then retrieval of information related to the satiated word would be effectively inhibited (see Morton, 1979 , for details of the principles of his model). Similarly, by adopting the assumption that prolonged activation can engender negative threshold changes or localized inhibition, models of spreading activation in semantic memory (e.g., Collins \& Loftus, 1975) can afford a framework in which the present data can be generally understood. The logogen and spreading activation accounts must handle the finding that category membership decisions with nonexemplars are not affected by satiation. One of many possible solutions to this problem is to suppose that subjects evaluate a target exemplar to determine the 
category (or categories) to which it may appropriately belong. If the taxonomic category for the target exemplar does not match (e.g., in a graphemic or phonemic code) the target category, a nonmember decision results. Therefore, within the present framework, nonmember decisions would not be affected by satiation of an unrelated category.

The covert retrieval and logogen/network models must address how theories of semantic priming in the lexical decision task might be constrained by the failure to obtain evidence for an effect of satiation with the priminglexical decision task. The core of many models of lexical priming (e.g., Collins \& Loftus, 1975) is the postulate that priming relies on activation of units in semantic memory. From the perspective of the present experiments, such models of lexical priming seem inadequate if we accept the position that the satiation treatment, by some mechanism, inhibits activation of semantic information related to the satiated word. One convergence of the category membership and priming-lexical decision experiments implies that priming in the lexical decision task is not mediated by "semantic" structures. A counter to this statement is to suggest that priming in the lexical decision task may be effected in some other strata of the semantic system. Alternatively, one other account of the present data escapes this conundrum.

Using the semantic network framework, a third account of the data from the category membership and priminglexical decision experiments is based on the assumption that satiation reduces the speed of spread activation and research in the satiated category's structure. In other words, we assume that the rate of flow of activation along a link between nodes in memory is reduced (the "sluggish link" hypothesis) when that link is repeatedly utilized, as during satiation. Activation of nodes, however, is not in any way impaired. We also assume that the process of retrieving the name of the category of which a target exemplar is a member involves traversing links that connect the exemplar to the superordinate category. From these assumptions, it follows that satiation will increase the search time for member decisions and hence member RTs. Nonmember decisions would not be affected by satiation, since retrieval of the category name and the process of comparing the retrieved and primed category names does not involve the sluggish links within the structure of the satiated category. Finally, lexical priming would be expected to remain intact. This is because priming activation of exemplars would still occur during the satiation period, although the time for activation to arrive at exemplar nodes following each repetition would be inceased.

\section{REFERENCES}

Antos, S. J. (1979). Processing facilitation in a lexical decision task. Journal of Experimental Psychology: Human Perception and Performance, 5, 527-545.
Balota, D. A., \& Chumbley, J. I. (1984). Are lexical decisions a good measure of lexical access? The role of word-frequency in the neglected decision stage. Journal of Experimental Psychology: Human Perception and Performance, 10, 340-357.

BLAXTON, T. A., \& NeELY, J. H. (1983). Inhibition from semantically related primes: Evidence of a category-specific inhibition. Memory \& Cognition, 11, 500-510.

Brown, A. S. (1981). Inhibition in cued retrieval. Joumal of Experimental Psychology: Human Learning and Memory, 7, 204-215.

Cohene, L. S., Smith, M. C., \& Klein, D. (1978). Semantic satiation revisited with a lexical decision task. Memory \& Cognition, 6, 131-140.

Collins, A. M., \& LofTus, E. F. (1975). A spreading activation theory or semantic processing. Psychological Review, 82, 407-428.

Esposito, N. J., \& Pelton, L. H. (1971). Review of the measurement of semantic satiation. Psychological Bulletin, 75, 330-346.

Gorpon, B. (1983). Lexical access and lexical decision: Mechanism of frequency sensitivity. Journal of Verbal Learning and Verbal Behavior, 22, 24-44.

KeEle, S. W., \& NeILl, W. T. (1978). Mechanisms of attention. In E. C. Carterette \& P. Friedman (Eds.), Handbook of perception (Vol. 9). New York: Academic Press.

Martindale, C. (1981). Cognition and consciousness. Homewood, IL: Dorsey.

Miller, G. A. (1978). Semantic relations among words. In M. Halle, J. Brown, \& G. A. Miller (Eds.), Linguistic theory and psychological reality. Cambridge, MA: MIT Press.

MorTon, J. (1970). A functional model for memory. In D. A. Norman (Ed.), Models of human memory. New York: Academic Press.

MORTON, J. (1979). Facilitation in word recognition: Experiments causing change in the logogen model. In P. A. Kolers, M. E. Wrolstad, \& M. Bouma (Eds.), Processing of visible language. New York: Plenum.

Mueller, C. W., \& Watiuns, M. J. (1977). Inhibition from part-set cueing: A cue-overload interpretation. Journal of Verbal Learning and Verbal Behavior, 16, 699-710.

NeELY, J. H. (1977a). The effects of visual and verbal satiation on a lexical decision task. American Journal of Psychology, 90, 447-459.

NeEly, J. H. (1977b). Semantic priming and retrieval from lexical memory: Roles of inhibitionless spreading activation and limited capacity attention. Journal of Experimental Psychology: General, 106, 226-254.

Neely, J. H., Schmidt, S. R., \& Roediger, H. L., III. (1983). Inhibition from related primes in recognition memory. Joumal of Experimental Psychology: Learning, Memory, and Cognition, 9, 196-211.

NEILL, W. T. (1979). Switching attention within and between categories: Evidence for intracategory inhibition. Memory \& Cognition, 7, 283-290.

PACHELla, R. G. (1974). The interpretation of reaction time in information processing research. In B. H. Kantowitz (Ed.), Human information processing: Tutorials in performance and cognition. Hillsdale, NJ: Erlbaum.

RaIJMakers, J. G., \& ShIFFrin, R. M. (1981). Search of associative memory. Psychological Review, 88, 93-134.

RATCLFF, R. (1978). A theory of memory retrieval. Psychological Review, 85, 59-108.

Roeviger, H. L., III, \& NeEly, J. H. (1982). Retrieval blocks in episodic and semantic memory. Canadian Journal of Psychology, 36, 213-242.

Rosch, E. (1975). Cognitive representations of semantic categories. Journal of Experimental Psychology: General, 104, 192-233.

SeVERANCE, E., \& WaShBuRN, M. F. (1907). The loss of associative power in words after long fixation. American Journal of Psychology, 18, 182-186.

\section{NOTE}

1. Repetition also engenders an experienced phonological distortion (Esposito \& Pelton, 1971) of the word, which may require additional concentration in order that correct pronunciation of the word be preserved. 
Appendix

Category Names (Primes) and Exemplar Targets

\begin{tabular}{|c|c|c|c|}
\hline \multicolumn{2}{|c|}{ List 1} & \multicolumn{2}{|c|}{ List 2} \\
\hline Prime & Target & Prime & Target \\
\hline TIME & MINUTE & GEM & DIAMOND \\
\hline METAL & GOLD & ANIMAL & HORSE \\
\hline DOG & POODLE & CLOTH & COTTON \\
\hline COLOUR & BLUE & FUEL & OIL \\
\hline CRIME & MURDER & LIQUOR & SCOTCH \\
\hline WEAPON & GUN & FRUIT & APPLE \\
\hline SPORT & HOCKEY & WEATHER & RAIN \\
\hline MUSIC & JAZZ & BIRD & ROBIN \\
\hline VEHICLE & TRUCK & TOY & DOLL \\
\hline DANCE & DISCO & INSECT & SPIDER \\
\hline FLOWER & ROSE & DISEASE & CANCER \\
\hline TREE & MAPLE & FISH & SALMON \\
\hline SNAKE & COBRA & CITY & HALIFAX \\
\hline DRUG & HEROIN & PLANT & CACTUS \\
\hline FOOD & BREAD & COUNTRY & RUSSIA \\
\hline TOOL & HAMMER & MONEY & DOLLAR \\
\hline SPICE & PEPPER & SNACK & CANDY \\
\hline GAME & CHESS & DRINK & WATER \\
\hline CAR & FORD & SEAFOOD & LOBSTER \\
\hline MONTH & APRIL & EMOTION & LOVE \\
\hline GEM & HORSE & TIME & GOLD \\
\hline ANIMAL & COTTON & METAL & POODLE \\
\hline CLOTH & OIL & DOG & BLUE \\
\hline FUEL & SCOTCH & COLOUR & MURDER \\
\hline LIQUOR & APPLE & CRIME & HOCKEY \\
\hline FRUIT & RAIN & WEAPON & JAZZ \\
\hline WEATHER & ROBIN & SPORT & MINUTE \\
\hline BIRD & DOLL & MUSIC & TRUCK \\
\hline TOY & SPIDER & VEHICLE & DISCO \\
\hline INSECT & CANCER & DANCE & ROSE \\
\hline DISEASE & SALMON & FLOWER & MAPLE \\
\hline FISH & HALIFAX & TREE & COBRA \\
\hline CITY & CACTUS & SNAKE & HEROIN \\
\hline PLANT & RUSSIA & DRUG & BREAD \\
\hline COUNTRY & DOLLAR & FOOD & HAMMER \\
\hline MONEY & CANDY & TOOL & PEPPER \\
\hline SNACK & WATER & SPICE & CHESS \\
\hline DRINK & LOBSTER & GAME & FORD \\
\hline SEAFOOD & LOVE & CAR & APRIL \\
\hline EMOTION & DIAMOND & MONTH & GUN \\
\hline
\end{tabular}

(Manuscript received September 14, 1983;

revision accepted for publication April 7, 1984.) 